San Jose State University

SJSU ScholarWorks

Faculty Publications

Social Work

January 2013

\title{
Occupational Engagement and Health in Older South Asian Immigrants
}

Sheama R. Krishnagiri

San Jose State University

Erin Fuller

San Jose State University

Lesley Ruda

San Jose State University

Sadhna Diwan

San Jose State University, sadhna.diwan@sjsu.edu

Follow this and additional works at: https://scholarworks.sjsu.edu/social_work_pub

Part of the Social Work Commons

\section{Recommended Citation}

Sheama R. Krishnagiri, Erin Fuller, Lesley Ruda, and Sadhna Diwan. "Occupational Engagement and Health in Older South Asian Immigrants" Journal of Occupational Science (2013): 87-102. https://doi.org/ 10.1080/14427591.2012.735614

This Article is brought to you for free and open access by the Social Work at SJSU ScholarWorks. It has been accepted for inclusion in Faculty Publications by an authorized administrator of SJSU ScholarWorks. For more information, please contact scholarworks@sjsu.edu. 


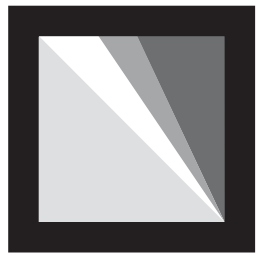

Sheama S. R.

Krishnagiri,

Erin Fuller,

Lesley Ruda \&

Sadhna Diwan

- Sheama S. R. Krishnagiri,

PhD, OTR/L, FAOTA,

Assistant Professor

Department of Occupational

Therapy, San Jose State

University, California, USA

- Erin Fuller, MS, OTR/L,

Graduate Student,

Department of Occupational

Therapy, San Jose State

University, California, USA

- Lesley Ruda, MS, OTR/L,

Graduate Student,

Department of Occupational

Therapy, San Jose State

University, California, USA

- Sadhna Diwan, PhD,

Professor, Department of

Social Work, San Jose State

University, California, USA

- Correspondence to:

sheama.krishnagiri@sjsu.edu

(C) 2013 The Journal of

Occupational Science

Incorporated

Journal of Occupational Science 2013

Vol. 20, No. 1, 87-102,

http://dx.doi.org/ $0.1080 /$

| 442759 |.20|2.7356 |4

\section{Occupational Engagement and Health in Older South Asian Immigrants}

The purpose of this study was to investigate the elements that shape how healthy active South Asian elder immigrants engage in daily activities to maintain their health. A descriptive grounded theory approach was employed using semi-structured interviews and a daily activity chart. Convenience sampling was used to recruit 12 South Asian elders, 7 males and 5 females, who immigrated after retirement to the South San Francisco Bay area. Open, axial, and selective coding of the transcribed data led to two broad themes, control and interdependence. These themes may be viewed as dynamic and interconnected forces that shape and determine the elder's choice and orchestration of daily occupations. They are mediated by the subthemes of social dynamics, cultural values, and health. Results indicate that well South Asian elder immigrants have a holistic and pragmatic outlook towards health, accept the constraints of their new environment and find ways to engage in healthy occupations. Their choice and engagement of occupations in turn facilitates adaptation to life in the United States. Barriers to health occur when the interdependent nature of lives and the individual control over occupational choices are out of balance or are disrupted.

Keywords: Elders, Immigrants, Occupations, Health

The relationship between meaningful occupational engagement and the health of an individual has been theorized in occupational science (Wilcock, 2006; Yerxa, 1998). Fundamental to the discipline are the notions that engagement in meaningful occupation not only meets biological needs but is essential for healthy adaptation, and that health should be "perceived as possession of a repertoire of skills enabling people to achieve their goals in their own environments" (Yerxa, 1998, p. 417).

One area of focus for occupational science is to understand the forces that shape occupation and how this affects health and quality of life through the lifespan. Specifically, focusing on the how and why of engagement in occupations, within the complexity of daily lives in context, should lead to a better understanding of this relationship (Yerxa, 2000). Individuals adopt daily routines that shape their lives, for example, in activities and rituals of social engagement, self-care activities, and meal preparation.

Older adults have been shown to spend time in three types of activities during the day that include obligatory activities (self-care and instrumental activities of daily living), leisure (television viewing, reading, and other activities), and 
rest (Horgas, Wilms, \& Baltes, 1998). Their choice of occupations is influenced by their desire to be active in society and fulfill expected roles (Nilsson, Lundgren, \& Liliequist, 2012). In addition, the engagement in at least one occupation that matters and provides a reason for being everyday appears to be related to aging well and health (Wright-St. Clair, 2012).

Immigration presents a major challenge to developing and establishing new occupational routines, especially for older immigrants who not only experience disruption of their former routines but also encounter limited English proficiency, lack of mobility, lack of awareness of community services, and lack of culturally relevant or responsive services (Trang, 2009; Treas \& Mazumdar, 2002).

This study explores how healthy South Asian (SA) elders, who immigrate later in life to the San Francisco bay area in the United States, choose and orchestrate their daily activities and maintain their health. Discerning how these elders develop meaningful acculturative responses is crucial to understanding the barriers and facilitators of health. Acculturation is the dynamic exchange between non-immigrant and immigrant people, in which lived experience and expectations have both negative and positive risk factors for health and co-existence (Abraido-Lanza, Armbrister, Florez, \& Aguirre, 2006). What the SA elders in this study identify as meaningful and influential in their daily lives should reveal the dynamic process of their engagement in health promoting occupations.

\section{Immigration \& South Asian Elders}

The term South Asian generally refers to those people who are culturally heterogeneous and originate from one of eight neighboring countries (e.g. India, Pakistan) in the Indian sub-continent; however US census data are not collected separately for these related groups. Since 1990, the Asian Indian born immigrant population (the largest group among SAs), in the US, grew by 1.2 million to become the third largest immigrant group after Mexicans and Filipinos (Terrazas \& Batog, 2010). About 43\% of new Asian Indian born immigrants arrive each year through family reunification visas for immediate relatives, many of whom are older parents of adult children (McKay, 2003). The top two cities in terms of the number of Asian Indian immigrants are San Jose and Fremont (Artz, 2011), where this study was conducted.

People who immigrate later in life experience disruption of their former routines that may prevent their participation in meaningful and health-promoting occupations (Becker, 2003). For elder immigrants, identity and healthy occupations emerge from multiple interactions between what people do daily and their sense of place, which can be complicated by narratives of loss and displacement (Becker, 2003; Huot \& Rudman, 2010). The increased risks for immigrants derive from language skills, healthcare access, unfamiliar cultural references, or personal and systematic discrimination (Casado \& Leung, 2002). However, the portrayal of elder immigrants as isolated, frail, and needy is not the complete story. The literature shows that older immigrants, in failing or good health, frail or not, constitute a rich cultural repository and play a vital role in their own care and the wellbeing of their families and their communities (Bhattacharya, 2011; George \& Chaze, 2009; Warnes \& Williams, 2006).

The risk of chronic diseases especially diabetes and heart disease increases for SAs who live longer in the US (Kalavar et al., 2004). Isolation, loneliness, boredom and life dissatisfaction amongst SA elders, deriving primarily from contradictory cultural expectations across family generations has been documented (Treas \& Mazumdar, 2002). Compromised mental health related specifically to the immigration process has also been found, with SA immigrants reporting post-immigration symptoms such as "stress," "tension," "loneliness," "depression," and "doing nothing" (Ahmad, Shik, Vanza, Cheung, George, $\&$ Stewart, 2004b). Anecdotal data gathered from community volunteers from the City of Fremont's 
Community Ambassador Program for Seniors (CAPS, 2010), indicates that many older SA late-life immigrants faced barriers to engagement in health promoting occupations. The barriers include limited English proficiency, transportation issues, lack of opportunities for socializing with peers, and lack of knowledge and access to community programs.

\section{Health Perceptions}

Regarding perceptions of health and health-related occupations, SA immigrants have markedly different underlying metaphors and philosophies of health and healing from mainstream Americans, and they view health holistically in terms of overall well-being, functionality, and happiness (Hilton et al., 2001; Karasz \& Dempsey, 2008; Oliffe, Grewal, Bottorff, Luke, \& Toor, 2007). Asian women source their health information primarily from their social, community, and religious networks and secondarily from their doctor. Information regarding health is more credible if in their native language, relevant to their situation, and from a trusted source (Ahmad et al., 2004a). They incorporate traditional practices into everyday life, including dietary regimes and home remedies dictated by the Ayurvedic, homeopathic, and naturopathic traditions (Hilton et al., 2001).

While SA immigrants attribute poor health to psychological factors, personal choice, and physical vulnerabilities, they also consider supernatural sources such as karma and the ill will of others (Jobanputra \& Furnham, 2005). God and religion surfaced multiple times in the literature as influences on illness and recovery; and some SA immigrants perceive the fate of their health as at least partly outside of their control (Hilton et al., 2001; Jobanputra \& Furnham, 2005; Oliffe et al., 2007; Wrightson \& Wardle, 1997). The importance of community is emphasized in the literature. Specifically, social support strongly influences an individual's participation in healthy activities and perceived health status (Jonnalagadda \& Diwan, 2005).

\section{Barriers to Healthy Aging}

Healthy aging, otherwise termed active aging by the World Health Organization (2002), is defined as "the process of optimizing opportunities for health, participation and security in order to enhance quality of life as people age" (p. 12). The literature on barriers and facilitators of health and active aging in the SA elder immigrant population is scarce. Furthermore, few studies agreed on barriers and facilitators, even when focused on single areas such as physical activity, mental health or diet. No studies have focused exclusively on SA seniors who immigrated to the United States as seniors. Thus, many barriers and facilitators identified may only apply to younger individuals or long time residents (Jonnalagadda \& Diwan, 2005; Misra, Patel, Davies, \& Russo, 2000). Bearing this in mind, along with the cultural diversity within SA communities, the literature suggests that the most common barriers to engaging in health-promoting occupations faced by the SA elder immigrant community are language restrictions, time constraints, lack of knowledge pertaining to medical diagnoses, poor communication with health professionals, and lack of motivation (Horne, Skelton, Speed, \& Todd, 2010; Kalavar, Kolt, Giles, \& Driver, 2004; Lawton, Ahmad, Hanna, Douglas, \& Hallowell, 2005; Lawton, Ahmad, Hanna, Douglas, Bains, \& Hallowell, 2008; Visram, Crosland, Unsworth, \& Long, 2008). These barriers prevent the elders from knowing, understanding, and choosing to engage in healthy occupations such as some form of exercise, healthy cooking, hobbies, and socializing. In a study of elder Asian Indian immigrants to Canada, significant barriers were shown to exist for this group when seeking and continuing with professional mental health care: cultural remedies lead to denial or noncompliance (Acharya \& Northcott, 2007). The most common barriers to seeking mental health services are family shame and the belief in karma, where mental illness is seen as the consequence of past deeds, and many Indian elders seek help only when the situation is critical (Contad \& Pacquiao, 2005). 
The literature on dietary practices in this population indicates that although foods and communal meals as cultural traditions present difficulties for making lasting dietary changes, some modifications for individuals with diabetes were made while maintaining the cultural aesthetics of food and dining together (Lawton et al., 2008). South Asians are also known to ascribe medicinal benefits to particular foods, which also may lead to non-compliance with western-based interventions (Pieroni, Houlihan, Anasari, Hussain, \& Aslam, 2007). This is germane since food preparation is an occupation often done by elder women to maintain cultural continuity, family cohesiveness, and to fulfill their role as respected elders. In addition, dining together is an occupation that provides meaningful identity and time for other collective occupations in extended families such as storytelling and talking with one another.

Several studies examined leisure and non-leisure physical activities and compared the elder immigrant group to native born elders, concluding that SAs were much less likely to engage in physical activity due to lack of motivation, understanding, and access (Kalavar et al., 2004; Kandula \& Lauderdale, 2005; Lawton et al., 2005; Visram et al., 2008). Increased length of residence in the West was found to facilitate physical exercise (Jonnalagadda \& Diwan, 2005; Misra et al., 2000).

To summarize, the literature indicates that SA elder immigrants experience loneliness, isolation, boredom, compromised mental health, and dissatisfaction with their lives in their new environment. They face a variety of barriers to engaging in health promoting occupations due to cultural values and beliefs that influence their choices of occupations, lack of knowledge about health and healthy activities, and lack of motivation. Furthermore, research has focused on individual activities as an element of health, such as physical activity, but no literature was found delineating how active and healthy elders determine and orchestrate their daily complement of occupations. Considering that health and health percep- tions are heavily influenced by culture and environment, and that underlying philosophies, metaphors, and perceptions regarding the locus of control of health in the South Asian community differ markedly from those in the mainstream United States, it is crucial to ask the following research question: How do healthy active SA elder immigrants engage in their daily occupations to maintain their overall health? An understanding of these factors in active healthy people will assist in more culturally appropriate programming for the larger community.

\section{Methods}

This pilot study was approved by the University's Institutional Review Board for human subjects' research to ensure ethical standards. A grounded theory approach was selected in order to allow emerging data to answer the research question without being influenced by pre-existing knowledge of the subject (Polit \& Beck, 2008). Data were collected via in-depth interviews and a daily activity chart. The interview guide consisted of questions centered on detailed descriptions of daily occupations, perceptions of health, and factors that impact health maintenance. The daily activity chart asked for their occupations hour by hour for a typical day. The interviews were conducted at the seniors' homes or at a community center and lasted approximately 2 hours each. No follow up interviews were conducted.

Present at each interview was the primary author who conducted the interview and one of three graduate student researchers. The student's role was to listen, take memos on salient points, observe, and assist with recording of data. Occasionally, the student researcher asked questions to clarify responses due to the accents of the interviewees. The primary author is of SA origin and familiar with the cultural nuances of language and accents. To verify information and to make transcription easier, the participant responses were purposefully repeated and questions were asked in multiple forms for enhanced accuracy. Field notes were taken after every interview and recruitment session at the community 
centers to document the researchers' informal observations of affect, dynamics between the couple, feelings, and initial thoughts. Debriefing after each interview and recruitment session followed.

\section{Procedures}

Convenience sampling was used to recruit participants. An announcement requesting volunteers was made by the researchers at several SA senior activity groups held by the Asian India Community Center. The center, the only one of its kind in the US, was built using private funds and serves the entire community, not just seniors. In addition, referrals from peer mentors in the Community Ambassadors Program, mentioned previously, were used. A total of 12 individuals were interviewed who met the inclusion criteria of being 60 years or older, immigrants to the United States after the age of 50, from India or Pakistan, English speaking, and active in the community.

The participants included five couples and two males. Although those men were married, one spouse was unavailable and the other could not speak English. The majority of interviews were conducted in the seniors' homes. While the intent was to interview individuals, the spouses requested to be interviewed at the same time. Due to the length of their marriages, the interweaving of routines amongst couples, and respect for their time and their age, the researcher assented to this request. The participants were cooperative and answered questions independently and by turn. That is, one member of the couple answered all the questions first and then the other. The researchers reflected on the process after the first interview and concluded that having both members of the couple present in the interview was helpful. Firstly, while the elders narrated the history of their lives and previous occupations, each asked the other for assistance with details or memory of an event. They pieced the story together with collective accuracy of their memories, sometimes after slight debate. Further, observations on the dynamics of the couple's relationship, the differing influences on their daily occupational choices, and understanding how the couple perceived and narrated their life story before and after migration added significantly to the data and was invaluable in the analysis.

Each interview was transcribed by one researcher and crosschecked by another. In addition, each of the four researchers independently coded all interviews at the open and axial coding stages to increase trustworthiness (Cresswell, 2007). All members met to discuss and agree upon the 63 open codes before progressing to the next step of categorization. Once the axial codes were generated independently, the investigators met and agreed on seven categories. Of these, two were identified as major unifying themes. Discussion ensued on the relationship of the themes to the other categories. Finally, the daily activity chart data was crosschecked with interview data for dependability and results were compared to the literature. Member checking was not conducted due to time constraints of the researchers and limited access to several of the participants.

\section{Results}

The participants in the sample ranged in age between 61 and 89 and included seven males and five females. All immigrated to the United States at age 55 or later, after retirement. All males were well educated and had held high positions in their careers in their country of origin. Two women held jobs outside the home earlier in life. No participants were currently employed, and all were generally financially dependent on adult children with whom they resided in predominantly upper middle class homes. Any savings or pensions from their country of origin were not spoken of. Religions represented included Hindu, Muslim, Sikh and Zoroastrian. Overall, the sample was relatively healthy and active in the community.

\section{Interdependence and Control}

From the descriptions of daily occupations and discussions of environmental influences on health, two strongly interlinked themes emerged from the data: interdependence and control. 
These themes may be viewed as dynamic forces that shape the daily occupations of these elders as they are moderated by the sub-themes of social dynamics, cultural values, and health factors. The expression of interdependence and control can be seen through participants' description of the how and why of all daily occupations including dietary practices, leisure, physical activities, and community interactions. Further, these forces are seen as determining the seniors' occupational choices and guiding the orchestration of daily routines.

The theme of interdependence is defined here as two or more people dependent on each other. Having immigrated to the homes of their adult children, after retirement, these elders became members of a multigenerational home in the new country and are no longer heads of households. Their daily routines and engagement in occupations became dependent on relationships with spouses, children, grandchildren and peers, as well as connections to people in their country of origin. Additionally, the cultural values dominant in the household, including values adopted from the new country by the adult children, shifted certain roles, expectations, and available resources. These elements both facilitated and limited the elders' choice of activities, leading to the notion of control, the second theme. Control is defined as a means of limiting or regulating an activity, tendency, or phenomenon (Locus of control, n.d.). In this study, data reflect internal and external loci of control: internal locus being when the agency of control lies within the individual and external when the agency lies outside the individual. Words used to indicate control are balance, discipline, restriction, following proper instructions, principles, and rules. These two themes are implicit in one other. That is, control is implicit in interdependence and interdependence is implicit within control. For example, increased dependence in one area may shift an individual towards an external locus of control that alters how he or she engages in that occupation. Therefore, the themes will be discussed together as they are moderated by each sub-theme.

\section{Social Dynamics}

In this sample, the relationships and interactions within the home between all three generations is the major factor that determines the feeling of interdependence for these participants. These dynamics impact their choice of occupations. The sense of having to adapt and be dependent on others challenges these elders as they learn to create new ways of being, owing to their modified authority, and no longer being heads of their households. The particular relationships with family members, peers, and spouses and the attendant role expectations reinforce new identities and influence engagement in occupations. As 73-year-old Mr. V. put it, "The juniors come with their children... and I'm uncle for them.... My daughter's friends and their wives, they need some advice and [my wife as elder] is there to give advice."

Further, while all participants reported interacting with and caring for grandchildren, socializing on the weekends when the adult children were free, connecting with family and friends in the old country, and assisting with household chores as part of their daily round of occupations, the timing and parameters of their occupations depended upon others. For example Mr. Y, who is 80 years old, spoke of waiting "for the evening. In the evening my son comes, we have dinner together." Mr. V. reported his wife, 62, waking at 5 a.m. for her prayers before having to "cook for the children." Routines changed, as explained by Mr. G., 70: "If I have to come to ICC [India Community Center] for a meeting, I will get ready early. If I am not to come, I will be slow." In essence, the elders abrogated control over the timing of their routines to fit in with what they had to do as part of the multi-generational family.

While most participants did not report family tensions, in a few instances the elders adapted routines to live harmoniously. This is evident in 71-year-old Mr. W's description of his relationship with the daughter-in-law:

Because she's done masters, she's engineer so she's got busy in her own profession, plus her 
daughter is in seventh grade so she prefers to spend more time with her, helping her, so we spend some time together by watching some evening show together as a family, but not ah (most of the time). We are understood each other, we are living for the last 10 years together so we know each other's needs, so there is no problem.

Instead of family activities, Mr. W. spends time volunteering in the SA community and socializing with peers.

The men's routines centered on their continued interests in news of India and Pakistan and the occupations of their wives. Spousal interdependence appeared vital for not only sharing thoughts and information but also holding onto familiar routines. Mr. G. explained, "Suppose I hear some news, then I will tell her. This is news, this is going on in India, this is happening. We are discussing world problems also (with wife)." Interdependence provides a sense of security in the new environment, evident here in 78-year-old Mrs. C.'s words, "My daughter and son, they are so very settled (here) and they take so good care of us. So we have nothing to worry."

All participants typically spent some time every day keeping in touch with family and friends overseas via email, Skype, or phone, and keeping abreast of news via the internet or TV. This connected them to their pre-immigration lives, maintaining relationships within that community, and being SA. In the words of 73-year-old Mr. V.:

I get up at 9 o'clock. She gets me some breakfast and tea. After that, most of the time, I have my computers and books. The best is the computer.... First of all, I read all the newspapers. Especially from Pakistan and India. See what is happening over there.

Regarding interactions with peers from the local community, Mrs. C.'s description underscored interdependence within her own community; "American seniors, we have no idea about their life actually. We have no communication with them. So, we have no knowledge about their ways." All participants echoed needing to be with others of the same culture and similar age, aware of themselves as interdependent social beings, and that social participation was natural and desirable for their mental wellbeing. Mr. V., 73, articulated it this way:

That means you cannot be aloof. You have to [be social], whatever is happening, it has its effect on the surroundings. Or whatever you are doing, you are being moderated by the surroundings. So, if you think that you can live alone, you'll go under depression.

These elders were aware of the socio-cultural differences between themselves and elders of other cultures and have chosen to meet peers of their own culture. Mr. C., 83, referred to the difficulties. "There are some groups, they meet some place, discuss some things, and talk some things.... Here, you're not able to meet them unless you go somewhere. We can't go every day to anybody's house." A consequence of their dependence on others and/or public transportation for mobility is the lack of spontaneous socialization. In their countries of origin, running into acquaintances at street corners or at shops was common. Taxis are expensive and not readily available in the suburbs where these participants live now. Mr. J., 89, who had back surgery and knee replacements, talked about finding ways to go out in to the community: "We could go on the buses and we have this lady who drives for us... and also Outreach" (public transport program for those with limitations). Others spoke of the distance and lack of transportation to the SA shops and the community center as prohibitive. Mr. V. explained:

You see, there's a difference in culture also. There in those countries, you had no barrier, in the sense that if you want to go to someone, just go out, ask for a driver - or if there's no driver, you go out and take a rickshaw... and a taxi...go anywhere you like... meet anyone you like. 
Given their expressed need for socialization and difficulty meeting up with peers of the same culture, these elders have adapted by socializing with their adult children's friends, finding other things to keep them occupied and using technology to keep in touch with their old friends. To quote Mr. C. "Because I can't get much people of my age, that's why I spend more time with the books.... The rest of the time the juniors come with their friends."

While certain components of the elders' lives lie outside of their locus of control due to interdependence, control was exercised through the ability, willingness, and self-awareness to adhere to exercise regimens, traditions and religious practices. Once the responsibilities related to family members' routines are completed, the elders are able to engage in their choice of occupations and routines such as morning tea, prayers, yoga, meeting friends, television, etc. Some of these occupations were reported to be the same as those in their previous life, while others are new. The majority reported doing some sort of physical exercise, prayer, leisure occupations such as reading, and communicating with family and friends in the old country. None of them complained about their feeling of dependence or shift in locus of control of their occupations. They accepted these constraints and their current role in the multigenerational family as part of the way life is in the United States. The lack of access to cultural peers for socialization and lack of independence in mobility were the main areas of dissatisfaction.

\section{Culture}

Traditional cultural perspectives and the adapted cultural values of younger family members influenced elder occupations in many ways. For example, information regarding healthy diet from the media and the younger generations guided dietary perceptions. As 73-year-old Mr. V. from Pakistan reflected, "The food patterns in those countries are quite different... mostly there [Pakistan], more fatty meats are preferred... all cholesterol bombs." Here an effort is made to prepare healthier choices, such as lean meats, while cooking traditional recipes to please all generations as they live and eat together, at least once a day. Religious and health restrictions exerted control over dietary practices. Mr. Y., 80, explained: "You see in our religion there are many do's and don'ts. We try to stick to those. Food also, for instance.... We will not touch anything where we doubt there is pork. And drink too. And only halal food." Traditional interdependent roles influenced the dietary and health choices. The choice of what is served and when is very dependent upon the knowledge and skills of the women. Mr. C., 83, admitted, laughing, "I don't cook anything. I don't know how to make even tea."

Adherence to traditional practices lay at an intersection of the external and internal loci of control. Where the willingness and ability to participate in religious ritual was internally motivated, the fate of health was often perceived to be in the hands of God. Mrs. G., 61, stated: "I will say this is God's gift also, I will thank that God also. Because he has given me...us so much... healthy life." Mr. and Mrs. G. spoke of faithfully following traditional healing practices, "We are going to ... a big center of naturopathy, of Ayurveda, and we go there and attend that for 10 days, and then be healthy." Mrs. C., 78, spoke here with irony, "My hobby is reading. So Cupertino library is something like temple to me."

Values and spiritual beliefs derived from strong bonds with the old country influence the elders' decisions to adapt their activity choices. For example, close-knit family is a value expressed by Mrs. C., "Joint family is very blessing," and by Mr. Y.'s description of contentment in old age. "You see, we are interested in our family... in my wife, I like them. That is good enough to keep me happy.... They're all well behaved, give me respect and attention. So I have nothing to complain (here)."

The desire to preserve their culture and being aware that they not only belong to their country of origin but also their adopted countries motivated occupations. Mr. W., 71, described two worlds, "I am in touch with the world affairs, and I know what happens in India, what happens here, 
so I'm trying to know both worlds." Given that many could only communicate in English with their grandchildren and did not have access to many peers who spoke their languages, they try to maintain their cultural and linguistic connections. As Mr. G. put it:

I have a number of friends who are in India, and we are talking with them also in my language. Every week or 10 days we talk to them. We are getting information on how they are doing because they are very good friends of mine.

Cultural norms and expectations also played a part in accessing health care and other community services. The lack of flexibility when seeking professional help was expressed by Mr. V:

Here you have to have an appointment to see someone. Then when he's free, you're not free, you're free, he's not free, and one thing more. There, the people even used to pop in to offices, have a cup of tea, then this and that, what it is. You just can't go to anyone here.

\section{Health}

The ability to engage in daily activities is dependent on one's physical health and general well-being. Mrs. C., 78, who has sciatica and arthritis, expressed her health perceptions this way:

If the body's fit, then your mental, and other activities, you can participate in. The first thing is your body must be fit. It is most important. If you have something, you can't concentrate on anything, writing, reading, nothing. The thing is if it is severe, it will not allow you to do anything. [If you are well] then you can participate in anything you want to do, [and] others want you to do.

Routine engagement in physically demanding occupations was often perceived as necessary to health, and part of a personal regime, like yoga or aerobics, but also as more enjoyable when done with others. In 71-year-old Mr. W.'s words: "I go and do aerobics and zumba dance and...I enjoy, even Sunday morning they have class at 9 o'clock, 9 to10, so I go and enjoy my people." Several mentioned that weekend family outings involved exercise equivalent to their daily walk, as Mr. and Mrs. J. (89 and 81 years old respectively) said, "Sometimes we go out...we go out for shopping or grocery - Costco [retail store]. We can walk there." In the words of Mrs. V., 62, "We walk.... half hour is compulsory for us. We did that in India and we do it here." While others, like Mrs. Y., 70, reflected on exercise this way; "I think we should walk, but I don't do that."

In some cases, physical activity was determined by role expectations. Mr. V., 73, speaking of his wife said: "She doesn't get time to exercise because all the time she is running around looking after grandchildren. That's some exercise, looking after the cooking, some laundry, then there [is] ... feeding [the] two kids." For others, physical activity that involved their spouse and peers was more fun and motivating. As Mr. C. noted:

We go in the park and a lot of our friends [are] there. We stick together with them (when we are exercising). And we discuss all sorts of problems all over the world, including India.... A lot of gossip is there, and we enjoy all people. Jokes also.

Control surfaced when participants were asked about the meaning of health. Many defined health by the ability to participate in occupations without physical or psychological restrictions. Mrs. C., who has sciatica, said: "If I have to cook...my legs and back must suffer me to do it.... and if I want to go walk, my legs must carry me there." Mr. G. stated, "Healthy means physically healthy, mentally healthy, and emotionally healthy, and healthy in every way." Health is perceived as being free from the controlling influence of physical and mental pain or disability. Mr. V. reflected, "To me healthy is a carefree and normal life... where you don't have much of worries, sickness. You should be free from that." 
References were also made to outside influences on health. Discussing health maintenance, Mr. G. stated: "Meditation is a very powerful instrument. I will say instrument in the sense that it relieves you from all pains. And the pain can be anything in mind, in eyes, in body, in emotional disturbance, anything!" In the same manner, God was a controlling influence on health. Mrs. G., 61, commented, "I thank God that I am healthy, it is also very... favor to me... from God. I don't have any trouble or [worries]."

Most of the participants were aware of themselves and others in relation to healthy living. Mr. B., 72 years old, illustrates internal control when he says, "Especially as we grow older we should know our own limitations... I can't do some exercises that you do." However, for some, the control over health shifted from an internal locus, having the awareness, willingness and faith in their ability to affect their health, to an external locus of control, such as abdicating control to the aging process. As Mr. W., 71, stated:

You see aging, after 50 years...I consider our life, our body as a machine-driven. Like we buy a car, new car we do new, regular maintenance - as it gets old we become casual, we don't do that much service, so same as our own body, we don't take care of the body.

The elders were also aware of the interplay between habit and the internal locus of control; when speaking of dietary routine, Mr. C., 83, stated, "IIt is] 50\% habit, and 50\% how we are conscious of it." Mr. Y., 80, who has diabetes and a pacemaker, explained his independent orientation to the information provided at the health talks heard at a community senior center:

We listen to what they say, and they say the same thing what we already know. It's a refresher course.... Whatever suits us we do. It's good to see people that come and renew our memory as to what we should do, what we should not do, how to ... maintain our well-being.
In summary, the participants consistently explained their daily routines and rationales for occupations in terms that involved their interdependence with other people and the amount of choice or restrictions they faced, whether this involved diet, physical exercise, time of activity, transportation, health, or socialization.

\section{Discussion}

Understanding what individuals "need and want to do" is critical to explaining the relationship between occupation and health. This includes looking at how people conduct their daily lives in particular contexts, what they do or don't do and why (Hasselkus, 2006; Yerxa, 2000). In immigrant populations, especially those that immigrate as elders, the ability to adapt and establish routines in a new environment is important in determining health. That is, learning to maneuver in the new environment, finding out where one can meet peers from one's own culture, and learning ways to access social programs and community resources are key to a sense of control and choice. It has been shown that for those Asian immigrant elders who cannot navigate the new environment due to lack of resources, ties to responsibilities such as child care and household chores, or limited social connections, isolation, grief, loneliness, boredom, and dissatisfaction can result (Casado \& Leung, 2002; Choudhry, 2001; Treas \& Mazumdar, 2002). Overall, the active and healthy immigrant elders in this study have shown that key to a healthy and contented life is a holistic and pragmatic outlook towards health, an awareness of needing to adapt habits and routines to fit into the multi-generational family, and being able to find ways to stay socially connected as well as engage in a few satisfying occupations of their own choice. The central themes of control and interdependence underpin these elders' narratives of the how and why of their daily occupations and choices. Although immigration is a disruption, these participants have acculturated by preserving continuity of their identity across the passing of time and the changing of place, accommodating elements of their old life within their new life. 
The physical family home embodies an interdependent social space via the rituals and routines of family meals, meaningful passing of time, valued roles, responsibilities, and shared identity; it also provides individuals with personal space to rest and conduct personal rituals and leisure pursuits. As Becker (2003) theorized it, the family home embodies an interdependent social space with shared routines as well as a place representing an extension of self wherein a person feels emotionally and meaningfully attached in the world. In this way, the participants' choice of using the Internet and satellite television brings home India or Pakistan as a meaningful presence and present in their lives that can be discussed by the whole family and with those back home.

Acharya and Northcott (2007) found that Indian immigrant women talked about 'maximizing control over inner self', preventing mental distress, and maintaining a sense of self-worth by keeping busy. In this sample, both men and women talked explicitly about avoiding loneliness and boredom as vital to mental health. They spoke of the women being dutifully busy in the domestic and family routines of the household, and both men and women were active in their social life and religious rituals. However, these SA elders spoke of their lives in integrated reflective narrative and did not give an impression of following a preordained recipe for good health.

Health is perceived by these study participants, in terms of functional ability for daily occupations, including roles in the home, access to leisure and social participation, and as far as possible being free from physical and emotional pain and disability. The importance of an outside social network in the SA community, which was emphasized in the work of Ahmad et al, (2004a) and Jonnalagadda and Diwan (2005), was also apparent with these elders. Beyond socializing with their children's friends, all participants are involved in the occupations of the various culturally based senior groups in the community, and continue to keep in touch with their friends in the old country.
Kalavar and Van Willingen (2005) asserted that SA Indian elderly undergo dramatic changes when moving from India to the US: many feel a loss of resources and an absence of accumulated personal accomplishments. Women are involved in caring for their grandchildren, and elderly men spend more time doing housework than they did while living in India. Further, they feel they have inadequate relations with neighbors due to linguistic, cultural, and religious barriers. Isolation occurs while their children and grandchildren are at work or school, and social encounters with other peers occur much less frequently than in India. This sample reported similar experiences to those in Kalavar and Van Willingen, however, they also identified these as constraints in their new life which they cannot change, and problemsolved ways to meet their needs for activity and socialization. The awareness of their own need to be occupied, and finding ways to do that, speaks to their adaptive skills. It is to be noted that these participants were highly educated and held high positions in their careers and therefore may be better positioned with skills necessary for finding and accessing resources.

The participants in this study spoke of lack of accessible transportation, loneliness, economic disadvantage, and lack of discipline as barriers to health for other members of their community. However, having spousal companionship, upper middle class living status, and education mitigates these issues. Higher levels of education mediate mental health (Lum \& Vanderaa, 2010). Further, in agreement with Treas and Mazumdar (2002), this study found that some elder SA immigrants, usually couples or men alone, confronted boredom or family tensions by opting out of interdependent family life at times to do what they wanted to do. Access to transportation, community services, and English language skills appear to be essential in these endeavors.

During the interviews, most women were less vocal and individuated than their husbands. It cannot be concluded from the data that they concur with all of their husbands' opinions. In this regard, Choudhry (2001) found that elder SA 
women living in the new country, compared to back home, may have fewer opportunities on their own than male peers on their own, or when in couples. Other studies of women's perceptions show that gender-specific concerns, especially in mental health, are crucial (Ahmad et al., 2004b; Diwan \& Jonnalagadda, 2002) for further research. The implication, therefore, is that within this older immigrant population, lack of cultural continuity, instability in the family home, or dysfunction in interdependence can lead to diminished role identity, and feelings of loss and isolation. These are risk factors for depression and migratory grief (Casado \& Leung, 2002). Jonnalagadda and Diwan (2005) concluded that programs for improving the health behaviors of this community need to focus on increasing the individual's perceived control, perception of social support, and mental well-being. Healthcare policy that seeks to facilitate how elder immigrants can access their own resourcefulness in daily occupations must understand the strengths and constraints affecting the whole family and community, including gender bias and marital status.

In this study, internal locus of control was exercised through the ability, willingness, and self-awareness to adhere to regimens, including diet, exercise, traditional healing practices, prayer, and religious ritual; sustain family and community roles; and seek balance. Multiple studies found that SA women identify their own self-discipline in their health through dietary regulation, exercise, traditional health and religious practices (Hilton et al., 2001; Karasz \& Dempsey, 2008; Oliffe et al., 2007). Dysfunction of internal locus of control, expressed as lack of 'control over inner self' in the study by Acharya and Northcott (2007), can translate into diminished feelings of belonging and lack of selfefficacy in healthy occupations.

External locus of control is exerted through beliefs, including religious beliefs, role patterns, dietary proscriptions, and traditional cultural values balanced with expectations of living in the United States. Fate, God, or karma emerges as aspects of health outside of an individual's control (Jobanputra \& Furnham, 2005; Wrightson \& Wardle, 1997). When food preparation is the duty of many family members, and people adhere to habitual foods for communal meals, specific dietary needs for an individual can be overlooked (Pieroni et al., 2007). This pilot study did not confirm or deny these findings. However, dysfunction in external locus of control manifests in family discord and role disruption, and can be exacerbated by inadequacy of culturally relevant resources, including medical care, information access, and social and linguistic supports. Ahmad et al. (2004b) linked mental health concerns to immigration and the resettlement process, pointing to loss of social support, economic uncertainties, downward social mobility, mechanistic lifestyle, barriers in accessing health services, and climatic and food changes.

Balance between external and internal loci of control maintains a sense of self-efficacy for these elders while relieving the burden of stress or 'worries' on the family and the individual. Interdependence increases acceptance of the family member who needs more care or support. Even though concern for being a burden was expressed by some elders, this pilot study indicated that these families seemed adept at managing the transition crisis, and that control and interdependence together provided robust reinforcement expressed via the daily complement of occupations. However the findings of Kalavar and Van Willigen (2005) suggest that the shift in power relations for some SA elders immigrating to their children's home can lead to loss of self-efficacy and family tensions. Inevitably this forces changes in daily occupations in the sense of what people "want and need to do." Barriers to engaging in occupations that lead to being healthy appear when interdependence with the family/community and individual control are out of balance.

\section{Limitations}

The study's main limitation lies in its sociocultural specificity: it was conducted with a small group of well elder SA immigrants, highly educated, English speaking, and living in upper middle class homes in one area of the United 
States. However, the factors that enable this group to acculturate and feel healthy are powerful and speak to the nature of human resiliency and adaptive skills. Comparable studies of SA elder immigrants from other parts of the country with varying levels of fluency in English, levels of education, and socio-economic status are required to enhance transferability.

It is also acknowledged that convenience sampling and self-report may have led to a variety of biases and omissions in the data. Further, the age category of $61-89$ is too broad to generalize to the health of all elders. Given that there are few organized community programs for this population, and limited awareness of and access to them by the immigrant elders, it is difficult to recruit in random fashion and specific age groups. Further, the joint interviews of couples which may encourage or suppress a participant's candor or input, and the gender, age, and ethnicity of the interviewers may bias the results. While the decision to interview couples has been explained, it appears retrospectively that the joint interview significantly benefitted the information gathered. The context of conducting interviews in the participants' homes with the conventions of hospitality may also bias content and interpretation of data. The procedures set in place to increase trustworthiness should address several of the biases mentioned.

\section{Conclusions}

By postulating that control and interdependence serve as integral forces that shape the participants' daily lives, this study expands upon the ideas in the literature known to influence occupational engagement and well-being in SA elder immigrants. These constructs represent the seniors' perceptions and struggles with new routines and acculturation in a new environment. Additionally, the role of these dynamic forces in how an individual chooses and orchestrates his or her daily occupations is important to understanding how healthy occupational engagement occurs in SA immigrant elders. Lessons from this welladjusted group not only include ideas of what resources this community needs, such as accessible social events, but also what they bring culturally to the transitional experience that assists in a healthy adaptation, namely holistic outlook, pragmatism, and an acceptance of their new role and constraints. These key factors may not be unique to SA elders but more generally applicable to later life immigrants from a variety of cultures. Comparing this immigrant group to SA elders who have grown old here, elder immigrants from other cultures, and Caucasian elders with respect to interdependence, control, and the role of the family would be worthy.

Further research needs to seek out SA elder immigrants from a broader age range, with different socio-economic circumstances and linguistic skills, in less good health, and with less supportive family situations, such as widowed spouses. Given the interdependent nature of SA elders with their families, future research might also take into account how the immigration of elder parents affects family health and occupations as a whole, including critical interviews with the children of these elders.

\section{Acknowledgements}

The authors would like to acknowledge the contributions of Chris M. Kreutzer, as a member of the research team in conducting the study.

\section{REFERENCES}

Abraido-Lanza, A., Armbrister, A., Florez, K., \& Aguirre, A. (2006). Toward a theory-driven model of acculturation in public health research. American Journal of Public Health,
96(8), 1342-1346. doi:10.2105/AJPH.2005. 064980

Acharya, M. P., \& Northcott, H. C. (2007). Mental distress and the coping strategies of 
elderly Indian immigrant women. Transcultural Psychiatry, 44(4), 614-636. doi:10.1177/13634 61507083901

Ahmad, F., Shik, A., Vanza, R., Cheung, A., George, U., \& Stewart, D. E. (2004a). Popular health promotion strategies among Chinese and East Indian immigrant women. Women \& Health, 40(1), 21-40. doi:10.1300/J013v40 n01_02

Ahmad, F., Shik, A., Vanza, R., Cheung, A.M., George, U., \& Stewart, D. E. (2004b). Voices of South Asian women: Immigration and mental health. Women \& Health, 40(4), 113-130. doi:10.1300/J013v40n04_07

Artz, M. (2011, May 11). Indians outnumber Chinese in Fremont [homepage on the Internet]. Tri-City Beat. Retrieved from http://www.ibabuzz. com/tricitybeat/2011/05/11/indians-outnumberchinese-in-fremont/

Asian American Justice Center. (2006). A community of contrasts: Asian and Pacific Islanders in the United States. Retrieved from: www. advancingequality.org/files/ComCont.pdf

Becker, G. (2003). Meanings of place and displacement in three groups of older immigrants. Journal of Aging Studies, 17(2), 129-149. doi:10.1016/S0890-4065(03)00007-0

Bhattacharya, G. (2011). Is social capital portable? Acculturating experiences of Indian immigrant men in New York City. Journal of Intercultural Studies, 32(1), 75-90. doi:10.1080/ 07256868.2010 .524919

Casado, B. L., \& Leung, P. (2002). Migratory grief and depression among elderly Chinese American immigrants. Journal of Gerontological Social Work, 36(1), 5-26. doi:10.1300/J083v36n01_02

Choudhry, U. K. (2001). Uprooting and resettlement experiences of South Asian immigrant women. Western Journal Nursing Research, 23, 376-393. doi:10.1177/019394590102300405

Community Ambassador Program for Seniors. (2010, Dec 6). Community ambassador program for seniors. Retrieved from http://www.capseniors.org/index.html

Contad, M. M., \& Pacquiao, D. F. (2005). Manifestation, attribution, and coping with depression among Asian Indians from the perspectives of health care practitioners.
Journal of Transcultural Nursing, 16, 32-40. doi:10.1177/1043659604271239

Cresswell, J. W. (2007). Qualitative inquiry \& research design (2nd ed.). Thousand Oaks, CA: Sage.

Diwan, S., \& Jonnalagadda, S. S. (2002). Social integration and health among Asian Indian immigrants in the United States. Journal of Gerontological Social Work, 36(1), 45-62.

George, U., \& Chaze, F. (2009). "Tell me what I need to know": South Asian women, social capital and settlement. Journal of International Migration \& Integration, 10(3), 265-282. doi:10.1007/s12134-009-0102-3

Hasselkus, B. R. (2006). 2006 Eleanor Clarke Slagle Lecture: The world of everyday occupation: Real people, real lives. American Journal of Occupational Therapy, 60(6), 627-640. doi:10.5014/ajot.60.6.627

Hilton, B. A., Sukhdev, G., Neleena, P., Bottorff, J. L., Johnson, J. L., Clark, H., . . Sumel, P. (2001). The Desi ways: Traditional health practices of South Asian women in Canada. Health Care for Women International, 22, 553-567. doi:10.1080/ 07399330127195

Horgas, A. L., Wilms, H., \& Baltes, M. M. (1998). Daily life in very old age: Everyday activities as expression of successful living. The Gerontologist, 38(5), 556-568. doi:10.1093/ geront/38.5.556

Horne, M., Skelton, D., Speed, S., \& Todd, C. (2010). The influence of primary health care professionals in encouraging exercise and physical activity uptake among White and South Asian older adults: Experiences of young older adults. Patient Education and Counseling, 79, 97103. doi:10.1016/j.pec.2009.04.004

Huot, S., \& Rudman, D. L. (2010). The performances and places of identity: Conceptualizing intersections of occupation, identity and place in the process of migration. Journal of Occupational Science, 17(2), 68-77. doi:10.1080/ 14427591.2010.9686677

Jobanputra, R., \& Furnham, A. (2005). British Gujarati Indian immigrants' and British Caucasians' beliefs about health and illness. International Journal of Social Psychiatry, 51(4), 350-364. doi:10.1177/0020764005060851 
Jonnalagadda, S. S., \& Diwan, S. (2005). Health behaviors, chronic disease prevalence and selfrated health of older Asian Indian immigrants. Journal of Immigration Health, 7(2), 75-83. doi:10.1007/s10903-005-2640-x

Kalavar, J. M., Kolt, G. S., Giles, L. C., \& Driver, R. P. (2004). Physical activity in older Asian Indians living in the United States: Barriers and motives. Activities, Adaptation \& Aging, 29(1), 47-67. doi:10.1300/J016v29n01_04

Kalavar, J. M., \& Van Willingen, J. (2005). Older Asian Indians resettled in America: Narratives about households, culture and generation. Journal of Cross Cultural Gerontology, 20(3), 213-230. doi:10.1007/s10823-006-9004-4

Kandula, N. R., \& Lauderdale, D. S. (2005). Leisure time, non-leisure time, and occupational physical activity in Asian Americans. Annals of Epidemiology, 15(4), 257-265. doi:10.1016/j.annepidem.2004.06.006

Karasz, A., \& Dempsey, K. (2008). Health seeking for ambiguous symptoms in two cultural groups: A comparative study. Transcultural Psychiatry, 45(3), 415-438. doi:10.1177/ 1363461508094674

Lawton, J., Ahmad, N., Hanna, L., Douglas, M., Bains, H., \& Hallowell, N. (2008). 'We should change ourselves, but we can't': Accounts of food and eating practices amongst British Pakistanis and Indians with type 2 diabetes. Ethnicity \& Health, 13(4), 305-319. doi:10.1080/13557850701882910

Lawton, J., Ahmad, N., Hanna, L., Douglas, M., \& Hallowell, N. (2005). 'I can't do any serious exercise': Barriers to physical activity amongst people of Pakistani and Indian origin with type 2 diabetes. Health Education Research, 21(1), 43-54. doi:10.1093/her/cyh042

Locus of control. (n.d.). The American Heritage ${ }^{\circledR}$ Stedman's Medical Dictionary. Retrieved September 04, 2012, from Dictionary.com website: http://dictionary.reference.com/browse/locus of control

Lum, T., \& Vanderaa, J. (2010). Health disparities among immigrant and non-immigrant elders: The association of acculturation and education. Journal of Immigrant \& Minority Health, 12(5), 743-753. doi:10.1007/s10903-008-9225-4
McKay, R. (2003, May 1). Family reunification. Migration Policy Institute. Retrieved from: http://www.migrationinformation.org/USfocus/ display.cfm? ID $=122$

Misra, R., Patel, T. G., Davies, D., \& Russo, T. (2000). Health promotion behaviors of Guajarati Asian Indian immigrants in the United States. Journal of Immigrant Health, 2(4), 223 230. doi:10.1023/A:1009544414050

Nilsson, I., Lundgren, A. S., \& Liliequist, M. (2012). Occupational well-being among the very old. Journal of Occupational Science, 19(2), 115-126. doi:10.1080/14427591.2011. 595894

Oliffe, J. L., Grewal, S., Bottorff, J. L., Luke, H., \& Toor, H. (2007). Elderly south Asian Canadian immigrant men: Confirming and disrupting dominant discourses about masculinity and men's health. Family and Community Health, 30(3), 224-236. doi:10.1097/01.FCH.00002 77765.54784 .46

Pieroni, A., Houlihan, L., Ansari, N., Hussain, B., \& Aslam, S. (2007). Medicinal perceptions of vegetables traditionally consumed by SouthAsian migrants living in Bradford, Northern England. Journal of Ethnopharmacology, 113, 100-110. doi:10.1016/j.jep.2007.05.009

Polit, D. F., \& Beck, C. T. (2008). Nursing research: Generating and assessing evidence for nursing practice (8th ed.). Philadelphia, PA: Lippincott Williams \& Wilkins.

Terrazas, A., \& Batog, C. (2010). Indian immigrants in the United States. Washington, DC: Migration Policy Institute. Retrieved from: http://www.migrationinformation.org/USFocus/ display.cfm? $\mathrm{ID}=785$

Trang, A. (2009). What older people want: Lessons from Chinese, Korean and Vietnamese immigrant communities. Generations, 32(4), 61-63.

Treas, J., \& Mazumdar, S. (2002). Older people in America's immigrant families: Dilemmas of dependence, integration, and isolation. Journal of Aging Studies, 16(3), 243-258. doi:10.1016/ S0890-4065(02)00048-8

Visram, S., Crosland, A., Unsworth, J, \& Long, S. (2008). Engaging women from South Asian communities in cardiac rehabilitation. 
International Journal of Therapy and Rehabilitation, 15(7), 298-304.

Warnes, A. M., \& Williams, A. (2006). Older migrants in Europe: A new focus for migration studies. Journal of Ethnic \& Migration Studies, 32(8), 1257-1281. doi:10.1080/136918306009 27617

Wilcock, A. A. (2006). An occupational perspective of health (2nd ed.). Thorofare, NJ: Slack.

World Health Organization. (2002). Active aging: A policy framework. Retrieved from http://www. who.int/ageing/active_ageing/en/index.html

Wright-St Clair, V. (2012). Being occupied with what matters in advanced age. Journal of
Occupational Science, 19(1), 44-53. doi:10.1080/14427591.2011.639135

Wrightson, K. J., \& Wardle, J. (1997). Cultural variation in health locus of control. Ethnicity $\mathcal{E}$ Health, 2(1/2), 13-20. doi:10.1080/13557858. 1997.9961811

Yerxa, E. (1998). Health and the human spirit for occupation. American Journal of Occupational Therapy, 52(6), 412-418. doi:10.5014/ajot.52. 6.412

Yerxa, E. (2000). Occupational science: A renaissance of service to humankind through knowledge. Occupational Therapy International, 7(2), 87-98. doi:10.1002/oti.109 